\title{
EI Mejor Derecho de Propiedad como Petitorio Implícito en las Demandas de Reivindicación
}

\author{
The Best Property Right as an Implied Request in the Claim Demand
}

\author{
Carlos Virgilio Vara Bejarano \\ Universidad Nacional Mayor de San Marcos
}

\section{INFORMACIÓN}

Historia del Artículo

Recepción: 19/05/2016

Revisión: 20/06/2019

Aceptación: 22/07/2019

\section{Palabras Clave}

Reivindicación, mejor derecho de propiedad, flexibilización principio dispositivo petitorio implícito

\section{Key Words}

Vindication, Right of Property, Implied Request

\section{DOI}

https://doi.org/10.35286/veritas. v21i1.252
Correspondencia:

Carlos Virgilio Vara Bejarano

varabejarano@gmail.com

\section{RESUMEN}

La Corte Suprema de la Republica del Perú, ha establecido como criterio en sus casaciones y un acuerdo plenario, que en las demandas de reivindicación, cuando las partes alegan derecho de propiedad, ya no deben ser declaradas improcedentes bajo el argumento, que previamente deben determinar quien tiene el mejor derecho de propiedad, sino que, allí mismo debe resolverse como punto controvertido. Ahora bien, cuando el mejor derecho de propiedad, es determinado como punto controvertido a efectos de resolver la reivindicación, este se ha sustanciado cual si fuera una pretensión, ejerciendo las partes las garantías que contienen el debido proceso, entre ellos el contradictorio y el derecho a la prueba, para hacer valer su derecho de propiedad y/o cuestionar el del otro, pero como no fue peticionado, no se puede emitir un pronunciamiento sobre el fondo, esto en merito al principio dispositivo por el que sólo las partes pueden incorporar el o los petitorios, debiendo hacerlo de manera clara y concreta, no admitiendo la posibilidad del petitorio implícito y el juez debe pronunciarse únicamente sobre lo peticionado. También la misma corte, estableció como criterio, que emitida la sentencia sobre reivindicación habiéndose determinado el mejor derecho de propiedad como punto controvertido, las partes pueden iniciar otro proceso por mejor derecho de propiedad, pues no hay cosa juzgada material sobre este último extremo. Conforme a lo expuesto, se tendría dos procesos, que por ser independientes podrían llevarse por separado o también acumularse, estando estas dos posibilidades sujetas a la voluntad de las partes, sin embargo de llevarse primero la reivindicación, para luego iniciar otro proceso por mejor derecho de propiedad, pudiendo resolverse ambas en un solo proceso, (sobre todo teniendo en cuenta la estrecha relación que tiene la una con la otra, donde el derecho de propiedad es el presupuesto principal), lo único que genera es dilación y costos innecesarios, tanto para las partes como para el estado mismo. Así expuesto, resultaría conveniente, en aplicación del principio de economía y celeridad procesal, atendiendo a los fines del proceso, que ambas pretensiones sean necesariamente acumuladas y que no se requiera la expresa voluntad de las partes para ello, es necesario entonces incorporar una formula normativa en el Código Procesal Civil, que flexibilice de este modo el principio dispositivo, para que faculte al juez a incorporar como petitorio implico, la declaración de mejor derecho de propiedad, cuando advierta de los fundamentos de hecho que ambas partes tiene derecho de propiedad, para de este modo tramitarlas como reconvención.

\footnotetext{
ABSTRACT

The Supreme Court of the Republic of Peru, has established as a criterion in its agreements and appeals, that in claim demands, when the parties claim property rights, they should no longer be declared inadmissible under the argument that they must previously determine who has the best property right, but right there, must be resolved as a controversial point. Now, when the best property right is determined as a controversial point to resolve the claim, it has been substantiated as if it were a purport, the parties exercising the guarantees that due process contains, including the audi alteram partem and the right to the test, to assert its property right and / or to question the other, but as it was not requested, a ruling on the merits can not be issued, this in merit to the principle by which only the parties can incorporate the or the petitions, having to do so in a clear and concrete manner [1], not admitting the possibility of the implied request and the judge must rule only on the petition. Also the court itself, established as a criterion that once the ruling on the claim has been issued, having determined the best property claim rights as a controversial point, the parties can initiate another process for better property rights, because ultimately there is no res judicata material on this point. As set out above, there would be two processes, which could be undertaken separately or accumulated, since these two possibilities are subject to the will of the parties concerned, however, if the claim takes place first, and then another process is initiated for better property rights, and both could be resolved in a single process, (especially taking into account the close relationship that one has with the other, where the property right is the main budget), the only thing that would be generated is delay and unnecessary costs, both for the parties as for the state itself. Thus stated, it would be convenient, in application of the principle of economy and procedural speed, taking into account the purposes of the process, that both claims are necessarily accumulated and that the express will of the parties is not required for it, it is necessary then to incorporate a normative formula in the Code of Civil Procedure, which in this way eases the principle, so that it allows the judge to incorporate the declaration of a better property right as an implied request, when he notes the factual grounds in which both parties have property rights, so as to process them as a counter-claim.
} 


\section{INTRODUCCION}

En las demandas de reivindicación, cuando el demandado cuenta con derecho de propiedad al igual que quien accionó contra él, puede en el mismo acto peticionar al juez que además de la reivindicación, también emita una sentencia declarativa por el mejor derecho de propiedad, es decir puede reconvenir. Sin embargo también está en la libertad de no peticionar tal declaración, limitándose a alegarlo como hechos a los efectos de contestar o absolver la demanda y lo afirmado en ella por el demandante, teniéndose entonces no como pretensión, sino únicamente como punto controvertido.

La Corte Suprema de Justicia de la República del Perú, en reiteradas sentencias casatorias y un Pleno Jurisdiccional $\mathrm{Nacional}^{2}$, ha sentado como criterio mayoritario, que en estos supuestos (cuando el mejor derecho de propiedad es alegado como argumentos de absolución), debe resolverse sobre el fondo únicamente por la reivindicación y que sobre el mejor derecho de propiedad, debe emitirse pronunciamiento como punto controvertido y que por tanto nada impide que resuelta la reivindicación de esta manera, puedan las mismas partes volverse a demandar por mejor derecho de propiedad, respecto del mismo bien, deviniendo en infundada la excepción de cosa juzgada que pudiera plantear la parte demandada ${ }^{3}$.

El presente trabajo está enfocado al supuesto descrito, es decir cuando el mejor derecho de propiedad fue alegado como argumento de absolución de demanda o de defensa y no como pretensión, para ello recoge la postura mayoritaria emitida por la Corte Suprema de Justicia de la República del Perú, al resolver los casos concretos, realizando un estudio de sus fundamentos, para finalmente desarrollar una crítica a la concepción tradicional del principio dispositivo en nuestro ordenamiento procesal civil y como es que en el caso expuesto, limita el cumplimiento célere y económico de los fines tanto abstractos como concretos del proceso, para finalmente sugerir que en el Código Procesal Civil, vía excepción pueda regularse el petitorio implícito en estos casos.

\section{Del criterio de la corte suprema de justicia de la república}

Cuando el demandado por reivindicación, al absolver el traslado alegue también tener derecho de propiedad, sin plantear reconvención, es deber del juez pronunciarse, dilucidar o determinar respecto del mejor derecho de propiedad de las partes, únicamente como punto controvertido y fin de resolver la demanda de reivindicación, tal como lo afirma la Corte Suprema de Justicia de la República del Perú, en sus reiteradas sentencias casatorias emitidas por la Corte Suprema de Justicia del Perú, que han abordado el tema, así tenemos: CAS N²937-2011 Arequipa; CAS N²509-2004
Tacna, CAS 698-2006 Lima; CAS No 1320-2000-Ica; CAS $\mathrm{N}^{\circ}$ 729-2006-Lima.

En igual sentido también se tiene del Acuerdo del Pleno Distrital Civil de la Libertad de Agosto de 2007 en el que se tuvo como tema a debatir "El mejor derecho de propiedad dentro de un proceso de reivindicación”, ante la pregunta : ¿En un proceso de reivindicación, puede discutirse el mejor derecho de propiedad, cuando el demandado también alega ser propietario del bien inmueble?, a lo que se votó en mayoría por la siguiente conclusión: "Se acordó que sí es procedente, resolver el mejor derecho de propiedad dentro de un proceso de reivindicación cuando el demandado al absolver la demanda se opone presentando su título de propiedad, obligando al demandante a pronunciarse sobre este hecho nuevo, y al Juez a fijar como punto controvertido en la audiencia respectiva: "determinar el mejor derecho de propiedad", punto controvertido que deberá ser materia de debate probatorio y posterior pronunciamiento por parte del Juez al momento de expedir sentencia; a fin de no vulnerar el principio de congruencia procesal previsto en el artículo VII del Título Preliminar del Código Procesal Civil y privilegiar de ese modo los principios de economía y celeridad procesal regulados en el artículo V del Título Preliminar del Código antes glosado, así como los principios registrales contenidos en el libro X del Código Civil; logrando de ese modo tanto la finalidad concreta como abstracta del proceso civil, que son resolver el conflicto de intereses con paz social en justicia."

Del mismo modo el Pleno Jurisdiccional Nacional Civil celebrado los días 6 y 07 de junio del año 2008, en el que se trató como segundo tema : "Reivindicación y Mejor Derecho de Propiedad" y que al someter a debate la pregunta: ¿En un proceso de reivindicación puede discutirse y evaluarse el mejor derecho de propiedad?, igualmente por votación mayoritaria se concluyo en lo siguiente: "En un proceso de reivindicación, el Juez puede analizar y evaluar el título del demandante y el invocado por el demandado para definir la reivindicación."

Este mismo razonamiento podríamos plantearlo de la siguiente manera: Si el pronunciamiento, determinación, dilucidación hecha por el A Quo, sobre el mejor derecho de propiedad a fin de resolver la demanda de reivindicación, no genera cosa juzgada material, ¿podrían entonces las mismas partes y sobre el mismo bien una vez concluido el proceso de reivindicación, iniciar un nuevo proceso en el que se peticione la declaración de mejor derecho de propiedad? o ¿podría en este nuevo proceso la parte demandada obtener una declaración de fundada la excepción de cosa juzgada?, la respuesta es afirmativa, es decir, sí podrían volver a demandar y la excepción de cosa juzgada devendría en infundada, conclusión también arribada por la Corte Suprema De Justicia De La República del Perú,

\footnotetext{
${ }^{2}$ Además también del Acuerdo del Pleno Distrital Civil de la Libertad de Agosto de 2007.

${ }^{3}$ Varios años atrás, al resolver estos casos la misma Corte Suprema, consideraba otro criterio, por el cual estas demandas eran declaradas improcedentes, en razón de que las partes debía previamente en el proceso correspondiente, debían lograr una sentencia declarativa de mejor derecho de propiedad y recién luego de ello plantear la reivindicación, por ejemplo en el Exp.497-96 Lima “(...) CONSIDERANDO: que es improcedente la demanda de autos, ya que la acción de reivindicación solo procede contra el poseedor no propietario, (...) no corresponde que en la presente acción se emita pronunciamiento alguno sobre el particular, por no tratarse de materia controvertida (...)", pero advirtiendo que al resolver de esa manera, muchos procesos luego de años de seguimiento y tramitación con los costos que estos implican, eran declaradas improcedentes incluso en etapa de sentencia, se opto por variar el criterio en ponderación de los principios de tutela jurisdiccional, economía y celeridad procesal.
} 
en la sentencia casatoria $N^{\circ} 2937-2011$ Arequipa $^{4}$.

Dentro de las consideraciones expuestas por la Corte Suprema de Justicia, en los citados fallos, en la que establece el criterio descrito, invocan como fundamentos principales, la aplicación de los principios de economía y celeridad procesal $^{5}$, tomando también en cuenta la relación que existe entre el derecho de propiedad y la reivindicación, que aunque el Código Civil, no se refiere a esta última, de manera clara en relación de su concepto y naturaleza, sino escuetamente la describe como el poder jurídico que permite la segunda ${ }^{6}$, empero ha sido mediante estos pronunciamiento que se ha desarrollado con mayor detalle.

Ahora, si bien el referido órgano jurisdiccional supremo, con el criterio citado alcanza los fines del proceso, tanto abstracto como concreto, sin embargo también debe considerarse que estos deben procurarse lograr en el más corto tiempo posible y con los menores costos, dentro del marco del debido proceso para las partes, siendo acertado el criterio de la Corte Suprema, pues al evitar declarar improcedente la demanda y llevar adelante el proceso para emitir un pronunciamiento respecto de la reivindicación, se logra el propósito, sin embargo, deja pendiente el pronunciamiento sobre el fondo, respecto de la declaración del mejor derecho de propiedad, que tendría que tomar un nuevo proceso para ser declarado, por ende un mayor tiempo y costo, que implican llevar estos dos procesos.

\section{¿Doble sustanciación?}

Establecido así, es decir tramitado como punto controvertido el mejor derecho de propiedad, dentro del proceso de reivindicación, no se diferenciaría de una demanda en la que se reconvino esta última, pues en ambos casos las partes cuentan con las garantías del debido proceso, que entre otras facultades, les permite ofrecer con libertad, todos los medios probatorios que considere conveniente, destinados a crear convicción de su derecho de propiedad, sujetos a la calificación del juzgador. El demandante lo hace al momento de postular su demanda y el demandado al momento de absolver el traslado o de postular su reconvención, si fuere el caso, teniendo en ambos supuestos las mismas libertades y garantías, por lo que no hay restricción alguna.

Respecto del derecho a la defensa e igualdad de armas, podemos advertir que las partes, al contestar los traslados correspondientes, pueden cuestionar los medios probatorios ofrecidos por la otra, accionando todos los mecanismos procesales de defensa, que establece la ley procesal civil, dirigidos a cuestionar el derecho de propiedad alegado por la otra parte, buscando hacer prevalecer el suyo, dando cuenta también que no existe diferencia y limitación alguna que pudieran tener las partes y específicamente hablando del demandado, en caso de que este se limite a absolver la acción dirigida en su contra o formule la reconvención peticionando al juez emita una declaración respecto del mejor derecho de propiedad.

Finalmente, respecto de la garantía de la debida motivación de las resoluciones judiciales, toda vez que el juzgador al emitir la sentencia en la etapa correspondiente, debe hacerlo con la debida valoración, es decir, la exposición de la forma en que los medios probatorios incorporados al proceso, le causan convicción de que el derecho de propiedad de una de las partes se prefiere por sobre el otro, con la única diferencia que el referido pronunciamiento en el caso de la reconvención, debe hacerse en la parte resolutiva y en el que se alega como argumento de absolución, en la parte considerativa.

$Y$ es que efectivamente, estamos ante dos casos similares, pero con efectos distintos, toda vez que en el supuesto en el que se reconvino, el juez podrá emitir dos pronunciamiento sobre el fondo con calidad de cosa juzgada material, uno de ellos declarando el mejor derecho de propiedad a favor de una de las partes y el otro por la reivindicación, pero en el supuesto que no se reconvino, únicamente podrá pronunciarse sobre el fondo con calidad de cosa juzgada por la reivindicación, recordando que la razón es que, en uno el demandado, ha formulado reconvención peticionando de manera clara y concreta, la declaración de mejor derecho de propiedad y en el otro únicamente ha absuelto el traslado de la demanda.

\section{El principio dispositivo y su flexibilización}

Urge aquí preguntarnos: ¿por qué tendría que llevarse en dos procesos, lo que bien podría resolverse en uno solo sin generar mayor costo?, si como hemos visto, el tramite del mejor derecho de propiedad como pretensión o como punto controvertido, es similar, la sustanciación será la misma, la convicción será la misma y el resultado sería también el mismo, por ejemplo, si uno tiene un derecho más antiguo que el del otro o si uno tiene un derecho inscrito y el del otro no, la aplicación de las normas del derecho civil para la prevalencia del uno sobre el otro, serán las mismas.

${ }^{4}$ CAS. N² 2937-2011 Arequipa “(...) SÉTIMO: Que, si bien es cierto, la demandante anteriormente ha interpuesto contra los demandados un proceso de reivindicación respecto del bien sub litis, el mismo que fue declarado infundado, éste no guarda similitud alguna con el presente proceso de mejor derecho de propiedad, por cuanto, en dicho proceso de reivindicación lo que se buscaba era la recuperación de la posesión del predio sub litis. Por tanto, teniendo dichos procesos pretensiones de naturaleza jurídica diferente, siendo la fundamentación fáctica en que se ampara la pretensión de mejor derecho de propiedad diferente a la de reivindicación, no se configura la triple identidad que requiere este tipo de excepción, ya que el objeto litigioso del anterior proceso (reivindicación) no es el mismo que el del actual, siendo además que las cuestiones fácticas en que se sustentan son diferentes; siendo esto así, la causales denunciadas deben ser amparadas. (...)”

${ }^{5}$ CAS. 3870-2015 LIMA. “(...) 1) Conforme a reiterada jurisprudencia emitida por la Corte Suprema de Justicia de la República y al Acuerdo adoptado por el Pleno Jurisdiccional Nacional Civil del año dos mil ocho, en el proceso de Reivindicación es posible analizar el mejor derecho de propiedad que le asiste a las partes, a fin de resolver la controversia mediante un pronunciamiento de fondo, cuando la demandada del proceso de reivindicación opone al demandante un derecho real de propiedad sobre el mismo bien de la demanda, en observancia a los principios de economía y celeridad procesal regulados en el Artículo V del Título Preliminar del Código Procesal Civil, con lo que se desestima el agravio referente a que la demanda debe ser declarada improcedente porque es jurídicamente imposible que se pueda desalojar en el proceso de Reivindicación a quien también tiene la calidad de propietario. (...)"

${ }^{6}$ Código Civil. Derecho de propiedad: Atribuciones. Artículo 923.- La propiedad es el poder jurídico que permite usar, disfrutar, disponer y reivindicar un bien. Debe ejercerse en armonía con el interés social y dentro de los límites de la ley. 
La respuesta es pues, por el respeto del principio dispositivo, el mismo que dentro de sus diferentes alcances y entendimientos, también nos informa que, dado el interés privado de las acciones civiles, como regla general, las partes serán las únicas en proponer el tema a decidir dentro de un proceso, siendo este el límite del juez para emitir un pronunciamiento sobre el fondo o material de la cuestión, acorde esta conclusión con el principio de congruencia procesal $^{7}$.

La referida regla, resulta de aplicación tanto para el demandante como para el que reconviene, así en el supuesto en estudio, el demandado por reivindicación, que alega tener derecho de propiedad del bien a reivindicar, podría o tiene la opción, si lo desea de formular reconvención postulando la pretensión de mejor derecho de propiedad y acumularse a la acción interpuesta contra él. Si optara por esa posibilidad, habría dos pretensiones en lugar de una sola y el juez deberá de resolver sobre el fondo, tanto por la reivindicación, como por el mejor derecho de propiedad, ambos en camino a tener la calidad de cosa juzgada material.

Para tener por formulada tal reconvención y tener por incorporada esta segunda pretensión de mejor derecho de propiedad, el demandado debe cumplir en su escrito, con por lo menos dos de los elementos fundamentales de la pretensión, que son a) los presupuestos de hecho y b) el petitorio. No abordaremos el requisito de los fundamentos de derecho, en merito a que nuestro Código Procesal Civil, se rige por el principio iura novit curia, por el cual las partes pudieran omitirla o invocarla erróneamente, siendo deber del juez, que conoce del derecho, aplicarla conforme a los hechos traído por las partes 8 , lo que no sucede con los fundamentos de hecho y el petitorio, que de ninguna manera puede incorporarla el juez, por ser una atribución exclusiva de las partes 9 .

Los presupuestos de hecho, que en ambos casos son distintos, así en el mejor derecho de propiedad, se requiere la existencia de dos propietarios con derechos opuestos y/o excluyentes, sin importar quien está en posesión del bien o si nadie lo posesiona, cuando en la reivindicación se requiere que el demandante tenga derecho de propiedad y que además el bien este en posesión del demandando, que no debe tener derecho de propiedad, entonces para recoger como petitorio el mejor derecho de propiedad, el demandado por reivindicación, debe alegar tener derecho de propiedad también, al igual que lo hizo quien lo demando por reivindicación, entonces habrían ya los dos títulos a confrontar, cumpliéndose el presupuesto de hecho exigido.

Pero ello no es suficiente, pues además debe formular su petitorio, entendido este ultimo como el efecto concreto sobre el que quiere que el juez se pronuncie o tema sobre el cual, luego de debatir, tenga que también decidir como otro extremo en el fallo. Adviértase también aquí que los dos petitorios tienen efectos distintos, así quien peticiona el mejor derecho de propiedad espera únicamente que el juez declare que su derecho es mejor que el del demandado (sentencia de tipo declarativa), pero en la reivindicación se peticiona que el juez imponga al demandado una obligación, que consiste en restituir en la posesión al demandante, (sentencia de tipo condenatoria), entonces si el demandado quiere reconvenir, además de contradecir o negar los hechos expuesto por el demandante por reivindicación, debe indicar de forma clara y concreta al juez, (accionar) que declare que su derecho de propiedad es mejor que del demandante por reivindicación.

Entonces, si el demandado únicamente, alega que no es un poseedor sin título, pues también es propietario, por lo que solicita se declare infundada la demanda por reivindicación, se tiene pues que no ha peticionado al juez un nuevo tema a decidir, habiéndose limitado a contestar o absolver lo alegado en la demanda, en este caso negándola, por lo que el juez únicamente se limitará a pronunciarse sobre el fondo respecto de la reivindicación, pues hay un solo petitorio, que es la del demandante por reivindicación, por tanto una sola pretensión y debe haber un solo pronunciamiento sobre el fondo o sustancial, que generará calidad de cosa juzgada material, en aplicación del principio de congruencia procesal.

En este último supuesto, habrá un pronunciamiento respecto del mejor derecho de propiedad también, pero en calidad de punto controvertido, como hechos alegados por la accionante y negados $\mathrm{u}$ opuestos por la parte demandada y que el juez tiene la obligación de pronunciarse, resolver o dilucidar, como también de motivar en la sentencia, sin embargo debe hacerlo en el ámbito de la obiter dicta, mas no en la ratio decidendi, no pudiendo este extremo adquirir la calidad de cosa juzgada material.

Los principios dispositivo ${ }^{10}$ y de congruencia procesal, se encuentran claramente y expresamente regulados en el Código Procesal Civil, en el articulo $424^{\circ}$ numeral 5, y el articulo

Entendido así los alcances del principio dispositivo al caso en estudio, podemos también concluir, que si bien el criterio expuesto por la Corte Suprema, cumple con los fines del proceso, es decir al final de los dos procesos, el que tiene el mejor derecho de propiedad será quien gane ambos y obtendrá la posesión del mismo, en justicia y paz social, sin embargo este se dará innecesariamente de un modo extenso en el tiempo y costoso, tanto para las partes como para los órganos de administración de justicia, que tendrán que realizar dos trámites procesales, entrando en escena para

\footnotetext{
${ }_{7}$ "Principio de Congruencia Es conocido como principio de consonancia. En virtud a este postulado se limita el contenido de las resoluciones judiciales; es decir, que deben emitirse de acuerdo con el sentido y alcance de las peticiones formuladas por las partes para el efecto de que exista identidad jurídica entre lo resuelto y las pretensiones, excepciones o defensas oportunamente deducidas. Es un principio que delimita las facultades resolutivas del Juez."(Grados, 2010)

${ }_{8 “}(\ldots)$ El juez no está obligado a seguir a los litigantes en sus planteamientos jurídicos; puede apartarse de ellos cuando los considere erróneos, invocando precisamente el iura novit curia porque son objeto de decisión los petitorios no las razones jurídicas que expongan. El juez debe dirimir la litis con la prescindencia de las alegaciones normativas efectuadas por los justiciables. Como lo señala peyrano (21) al juez le está vedado, dentro del un esquema procesal crudamente dispositivista, ser curioso respecto del material factico; pero puede, y debe, emprender una búsqueda sin fronteras, tendiente a subsumir rectamente aquel dentro del ordenamiento normativo. (...)"(Ledesma Narvaez, 2008)

${ }^{9}$ Código Procesal Civil. Título Preliminar. Juez y Derecho.- Artículo VII.- El Juez debe aplicar el derecho que corresponda al proceso, aunque no haya sido invocado por las partes o lo haya sido erróneamente. Sin embargo, no puede ir más allá del petitorio ni fundar su decisión en hechos diversos de los que han sido alegados por las partes.

${ }^{10}$ Código Procesal Civil. (...) Requisitos de la demanda. Articulo 424.- La demanda se presentara por escrito y contendrá: (...) 5) El petitorio, que comprende la
} determinación clara y concreta de lo que se pide (...)". 
ser nuevamente ponderados los principios procesales de economía y celeridad procesal.

Los principios procesales y el proceso mismo le deben su razón de ser a los fines que este persigue, de tal modo que no pueden confundirse entre ellos, entonces si el principio dispositivo establece, que solo las partes pueden incorporar las pretensiones, pero advertimos que en el caso en estudio, esta postura hace larga y costosa la solución del caso concreto, entonces ¿cuál es la razón o justificación de mantenerlo vigente o por lo menos en la concepción tradicional con la que está regulada en nuestro cuerpo adjetivo?, la posibilidad de dos procesos en lugar de uno, no contribuye a dar solución a la congestionada carga procesal que manejan los órganos jurisdiccionales en el Perú.

En el caso bajo estudio, la exigencia de que el petitorio deba formularse de manera clara y concreta, llevando a que el juez, como simple espectador se le mantenga en la imposibilidad de incorporar implícitamente el petitorio de mejor derecho de propiedad, cuando este se muestre necesario y evidente de los hechos de la contestación de la demanda, sobre todo por la relación que existe entre estas dos pretensiones, (pues el derecho de propiedad, es el poder jurídico que permite la reivindicación) es un esfuerzo por cumplir las formas, a costa de alcanzar los fines de manera más optima.

Resultaría entonces conveniente que mediante formula normativa en el Código Procesal Civil, se faculte al juez a incorporar como petitorio implícito, la declaración de mejor derecho de propiedad, cuando este advierta de los fundamentos de hecho expuestas por las partes, que oponen derecho de propiedad, corriéndoles previamente traslado de su decisión y tramitarla como reconvención, es decir en estos supuestos apartarnos de la concepción tradicional del principio dispositivo, recurriendo a una versión flexible a favor de la economía y celeridad procesal.

\section{CONCLUSIÓN}

Conforme al criterio de la Corte Suprema de Justicia del Perú, en los procesos de reivindicación, en los que el juez ha dilucidado, determinado o emitido pronunciamiento respecto del mejor derecho de propiedad como punto controvertido, con la finalidad de resolver la reivindicación, esta solo puede generar cosa juzgada material respecto de la reivindicación, mas no por el mejor derecho de propiedad, por lo que las partes pueden recurrir, luego de concluido el proceso de reivindicación a otro proceso de mejor derecho de propiedad, sin que prospere la excepción de cosa juzgada.

Tramitar el mejor derecho de propiedad como punto controvertido o como pretensión, son similares, pues en ambos supuestos las partes estuvieron en la plena libertad de ofrecer los medios probatorios que consideraron pertinentes, actuar todos los mecanismos procesales de defensa, cuestionar el derecho de propiedad de la otra parte, dentro de un debido proceso, buscando hacer prevalecer el suyo, con un juez que valoró las actuaciones probatorias y motivó la convicción de que el derecho de propiedad de una de las partes es mejor que el del otro.

Consecuentemente, resolver el mejor derecho de propiedad primero como punto controvertido para luego volver a sustanciarlo como pretensión, significaría doble trabajo, que si bien en ambos casos se cumplen los fines del proceso, sin embargo, esto hace que sea de manera prolongada en el tiempo y costosa.

Por ello en el caso expuesto y considerando que ambas pretensiones son intrínsecas pues la reivindicación es el poder jurídico que otorga el derecho de propiedad, resulta conveniente que en el Código Procesal Civil se regule, como excepción al principio dispositivo, la facultad del juez de incorporar como petitorio implícito, el mejor derecho de propiedad, cuando lo advierta de los fundamentos de hecho de la contestación, tramitándola como reconvención.

\section{REFERENCIAS BIBLIOGRÁFICAS}

1. Acuerdo Plenario Distrital de la Libertad. (2007). La Libertad.

2. Asociación Irrigadora y Colonizadora Yuramayo, CAS. N ${ }^{\circ}$ 2937-2011 AREQUIPA (Sala De Derecho Constitucional Y Social Permanente De La Corte Suprema De Justicia De La Republica 31 de Octubre de 2016).

3. Asociacion Union de Campesinos Jose Maria Arguedas, 3881-2012- PA/TC (Tribunal Constitucional Peruano 01 de marzo de 2016).

4. Aspillaga Anderson Hermanos S.A. 05614-2007 PA/ TC- Lima (Tribunal Constitucional 20 de marzo de 2009).

5. Carrion Lugo, J. (2007). Tratado de Derecho Procesal Civil. Lima: Grijley.

6. Chavez Guilerhua, 3464-2013, Lima Norte (Sala Civil Transitoria De La Corte Suprema De Justicia De La Republica 01 de Agosto de 2016).

7. Couture Etcheverry, E. J. (1958). Fundamentos del Derecho Procesal Civil. Buenos Aires: Roque de Palma Editor.

8. De Azcárate, G. (1883). Ensayo Sobre la Historia del Derecho de Propiedad y su Estado Actual en Europa. Madrid.

9. Devis Echandia, H. (1984). Teoria General del Proceso. Buenos Aires: Universidad.

10. Enciclopedia Juridica. (04 de Agosto de 2018). Obtenido de http://www.enciclopedia-juridica.biz14. com/d/causa-petendi/causa-petendi.htm

11. Enrique Palacios, L. (2003). Manual de Derecho Procesal Civil. Buenos Aires: Lexis Nexis.

12. Fernandez Cruz, G., \& Bullard Gonzales, A. (1997). Derecho Civil Patrimonial. Lima Peru: Fondo Editorial Pontificia Universidad Catolica del Peru.

13. Fix-Zamudio, H. (1974). Constitucion y Proceso Civil en Latinoamerica. Mexico 20 D.F.: Instituto de Investigaciones Juridicas UNAM.

14. Grados, G. A. (2010). Lecciones de Derecho Procesal Civil. Lima: San Marcos.

15. Gronda, J. D. (1976). Diccionario Juridico. Buenos Aires: Claridad S. A.

16. Hinostroza Minguez, A. (2007). Comentarios al Codigo Procesal Civil. Lima: Gaceta Juridica.

17. IV Cuarto Pleno Casatorio Civil, Casacion 2195-2011 Ucayali (Corte Suprema de Justicia De La Republica 13 de Agosto de 2012).

18. Izquierdo, A. G. (1996). La Propiedad como Derecho Fundamental. Derecho \& Sociedad, 36-42.

19. Jorge Avendaño Valdez. (2003). Codigo Civil Comentado por los 100 mejores especialistas (Vol. V). 
Lima: Gaceta Juridica.

20. Ledesma Narvaez, M. (2008). Comentarios al Codigo Procesal Civil. Lima: Gaceta Juridica.

21. Nemesio Echevarría Gómez, EXP. N. ${ }^{\circ}$ 0569-2003AC/TC (Tribunal Constitucional Peruano 05 de 04 de 2004).

22. Pavon, J. E. (2016). Derechos Reales (Primera Edicion ed.). Bogota: Universidad del Rosario. Obtenido de https://books.google.com.pe/books?id=Jl $0 \mathrm{yDwAAQBAJ} \&$ printsec $=$ frontcover $\& \mathrm{dq}=$ derechos + reales\&hl $=$ es-419\&sa $=X \& v e d=0$ ahUKEwirl9TdmP d $\begin{array}{llllllllllll}\mathrm{A} & \mathrm{h} & \mathrm{X} & \mathrm{w} & \mathrm{p} & 1 & \mathrm{k} & \mathrm{K} & \mathrm{H} & \mathrm{V} & \mathrm{E} & -\end{array}$ Ch8Q6AEINTAD\# $\mathrm{v}=$ onepage $\& \mathrm{q} \& \mathrm{f}=$ false

23. Payno, M. (1869). Tratado de la Propiedad. Mexico: I. Cumplido.

24. Pipes, R. (2002). Propiedad y Libertad. España: Turner Fondo de Cultura Economica.

25. Real Academia De La Lengua Española. (22 de Julio de 2018). http://www.rae.es/. Obtenido de http://dle. rae.es/?id=VnXRVds

26. Sanchez, R., \& Moralejo Inbernon, N. (2011). Property and trust law in spain.Gran Bretaña: Kluwer law International.

27. Sentencia del Pleno Jurisdiccional del Tribunal Constitucional del Peru, 030-2004 AI/TC (Tribunal Constitucional del Peru 02 de diciembre de 2005).

28. TERCER PLENO CASATORIO CIVIL, CASACION $\mathrm{n}^{\circ}$ 4664-2010 PUNO (Corte Suprema de Justicia del Peru 18 de MARZO de 2011).

29. Ticona Postigo, V. (1999). El Debido Proceso y La Demanda Civil. Lima: Rodhas.

30. Vide, C. R. (2005). http://revistas.ucm.es. Nueva Epoca. doi:ISSN: 1698-5583

31. Wikipedia. (15 de 07 de 2018). Propiedad. Obtenido de https://es.wikipedia.org/wiki/Propiedad

32. Wikipedia. (19 de agosto de 2018). Wikipedia. Obtenido de www.wikipedia.org: https://es.wikipedia. org/wiki/Estado_social 